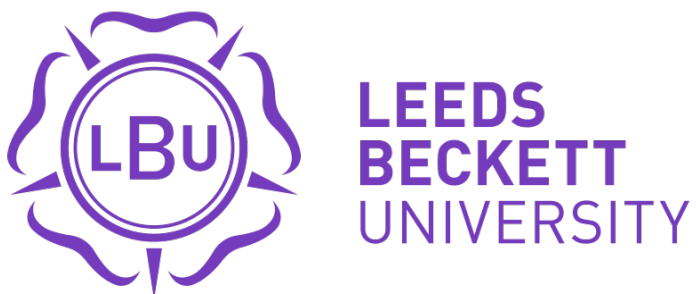

Citation:

Blackshaw, T and Long, $\mathrm{J}(2005)$ What's the big idea? A critical exploration of the concept of social capital and its incorporation into leisure policy discourse. Leisure Studies, 24 (3). 239 - 258. ISSN 0261-4367 DOI: https://doi.org/10.1080/0261436052000327285

Link to Leeds Beckett Repository record:

https://eprints.leedsbeckett.ac.uk/id/eprint/924/

Document Version:

Article (Accepted Version)

The aim of the Leeds Beckett Repository is to provide open access to our research, as required by funder policies and permitted by publishers and copyright law.

The Leeds Beckett repository holds a wide range of publications, each of which has been checked for copyright and the relevant embargo period has been applied by the Research Services team.

We operate on a standard take-down policy. If you are the author or publisher of an output and you would like it removed from the repository, please contact us and we will investigate on a case-by-case basis.

Each thesis in the repository has been cleared where necessary by the author for third party copyright. If you would like a thesis to be removed from the repository or believe there is an issue with copyright, please contact us on openaccess@leedsbeckett.ac.uk and we will investigate on a case-by-case basis. 


\title{
What's the Big Idea? A critical exploration of the concept of social capital and its incorporation into leisure policy discourse
}

\begin{abstract}
Starting from the overwhelming welcome that Putnam's (2000) treatise on social capital has received in government circles we consider its relative merits for examining and understanding the role for leisure in policy strategies. To perform this critique we identify some of the key points from Putnam's work and also illustrate how it has been incorporated into a body of leisure studies literature. This is then extended to a discussion of the methodological and theoretical underpinnings of his approach and its link to civic communitarianism. We suggest that the seduction of the 'niceness' of Putnam's formulation of social capital not only misses the point of the grimness of some people's lives but it also pays little attention to Bourdieu's point that poorer community groups tend to be at the mercy of forces over which they have little control.
\end{abstract}

We argue that if the poor have become a silent emblem of the ways in which the state has more and more individualised its relationship with its citizens, it is they who also tend to be blamed for their own poverty because it is presumed they lack social capital. This in turn encourages 'us' to determine what is appropriate for 'them'. As a critical response to this situation we propose that Bourdieu's take on different forms of 'capital' offers more productive lines for analysis. From there we go on to suggest that it might be profitable to combine Bourdieu's sociology with Sennett's recent interpretation of 'respect' to formulate a central interpretive role for community leisure practitioners - recast as cultural intermediaries - if poorer community groups are to be better included.

\section{Introduction}

We are fascinated by the way in which the concept of social capital has been accepted into the policymaking discourse and the name of Robert Putnam trips off the tongues of key decision-makers. Hall (2003), writing in the Guardian as we were discussing this paper, observed that Putnam's book 'Bowling Alone is required reading in Downing Street'. The acceptance of the social capital thesis in the UK was reflected, for example, in the 
government reviews of the 2001 'disturbances' (Cantle, 2001; Denham, 2001) ${ }^{1}$. Visits to web sites like those of the World Bank or the UK's Office for National Statistics also lend emphasis to this high status (see, for example, ONS, 2001; World Bank, 2003). The other important reason this attraction to social capital is of interest to us is that its major exponents, particularly Putnam (2000) but also Bellah et al. (1987), have stressed the value of sport and leisure associations for social capital, to such an extent that critics have chastised them for essentially reducing the idea of civil society to these at the expense of considering the impact of other kinds of social networks and institutions (Siisiäinen, 2000).

Although social capital - along with economic, cultural and symbolic capital - has featured extensively in the sociology of leisure and sport, mainly through the work of Pierre Bourdieu, none of these concepts has ever achieved much recognition in the United Kingdom (unlike in France) beyond the gates of the academy. Interest though has flourished in recent years, for the most part through the work of Robert Putnam, who breathed into the concept a reinvigorated political life, particularly through Bowling Alone, which develops some of his own earlier arguments on the topic (Putnam, 1993; 1995). Putnam acknowledges much earlier formulations of social capital, notably from a group of Canadian sociologists writing about the club membership of people moving to the suburbs and Jane Jacobs in her work on neighbourliness in modern cities. However, the interest in social capital goes back much further - Putnam identifies an educational reformer (Hanifan) during the First World War but its antecedents can be traced to the political and social thought of Alexis de Tocqueville and the sociology of Emile Durkheim. And what this observation suggests is that social capitalists have the same roots as proponents of communitarian political thought ${ }^{2}$.

Few other ideas so closely related to people's leisure lives have had such an impact as social capital is beginning to have today in the policy arena. In this paper we shall address our own challenge of working out why social capital (and by default communitarianism) should hold such appeal and assess its contribution with a three-pronged critique. After considering the relative merits of Putnam's social capital thesis, we critically discuss the methodological limitations of his research. This is followed by a discussion of the ideological dimensions of Putnam's project, which we describe as a version of civic communitarianism (Delanty, 2003). Although a detailed discussion of ideology is beyond the scope of this short paper, following Thompson (1984: 4) we understand ideology as comprising 'the ways in which meaning (or signification) serves to sustain relations of domination'. In the work of Putnam we regard 
ideology as operating at two broad levels. On one level it operates as an ideology-as-culture, which we argue is a body of political ideas representative of a particular social group (Seliger, 1976) described by Delanty (2003) as 'civic communitarians'. On another level, and after Bourdieu, we equate with this ideology a process of symbolic action (symbolic exchange, symbolic power and symbolic violence) which operates in tandem with the more explicitly material effects of civic communitarianism.

Third we outline a sociological understanding of social capital through the work of Bourdieu. This not only provides the theoretical backcloth against which we critically discuss Putnam's own interpretation of the concept, but it also allows us to outline the rudiments of our own counter perspective. Here we suggest that if Putnam's version of 'social capitalism' is largely inconsistent, there is a pivotal role for Bourdieu's sociology in the process of engaging with issues of social exclusion through leisure and we offer some tentative suggestions for an alternative policy agenda, which is not only alert to the cultural boundaries that divide local communities but also respectful of the differences that are characteristic of individuals who live in them.

There is a thread running through the paper that alerts us to thinking about the symbolic nature of Putnam's own project - that is the way in which it generates for Putnam and other like-minded communitarians their own social capital. We are concerned that what he offers is more an imaginary construction than a solution for the pains it claims to cure. What we want to argue is that the discourse surrounding the idea of social capital navigates far from the use of language as a set of uninformed conventions. We are instead subsumed within an ideology of word and world realism, the powerful effects of which, in terms of leisure policy, often bear little relevance to the worlds of those people they purport to care for.

\section{Putnam's Social Capital Thesis}

Focusing his nostalgic eye on the sport of bowling, Putnam (2000) observes that the bowling leagues of his youth with their legions of teams are no longer the dominant form of participation and that people now 'bowl alone'. Of course they rarely bowl alone, but in small, pre-existing groups such that the activity does not involve interaction with new people. 
This is taken to be symptomatic of a much more general shift (away from gregarious activity) causing social malaise in contemporary America.

Putnam offers a range of indicators which suggest that social interaction in America declined markedly in the latter part of the twentieth century with a consequent impact on the social capital taken to be fundamental to a productive society. Social capital derives from dense social networks and is characterised by generalised reciprocity (people contribute even when there may be no direct personal benefit). The notion of social capital that he expounded in association with this has two principal facets:

a) bonding, the ties and interaction between like people (inward looking and exclusive);

b) bridging, the inter-group links (outward looking and inclusive)

Putnam's conception of social capital has some further important characteristics

a) It is both a public and a private good in that I benefit from my contribution to social capital and so do others.

b) It is evidenced in many different forms - through family, neighbours, sports groups, church groups, personal social circles, civic organisations, and now e-groups. Some of these connections are repeated and intensive, some are episodic and casual; some are formal, some informal.

c) Its networks and reciprocity are 'generally good for those inside the network, but the external effects of social capital are by no means always positive’ (p22)

Putnam (2000: 21/22) does acknowledge that there is a dark side to social capital that may be used for anti-social purposes:

...urban gangs, NIMBY (“not in my backyard”) movements, and power elites often exploit social capital to achieve ends that are antisocial from a wider perspective.

Parallels might be drawn with the fiercely exclusionary practices of some sporting groups in which exclusivity is celebrated in the name of group/team solidarity and collective identity (Jarvie, 2003). Similarly, Putnam (2000: 17) offers a note of caution that the peak of civic activity and social connectedness occurring in North America in the 1950s and 1960s was 'hardly a 'golden age', especially for those Americans who were marginalized because of their race or gender or social class or sexual orientation'. Social capital may operate to 
impose conformity and social division at the expense of tolerance. However, this dark side is sidelined in the subsequent consideration of the operation of social capital, and Putnam's underlying belief is that social capital underpins a more productive, supportive and trusting society to general benefit - that society's mechanisms operate more efficiently when there is more social capital.

Putnam then marshals evidence from across the US to chart fluctuations in the stock of social capital, seek explanations for such changes and assess the impact on social processes and benefits. The data he uses are drawn from organisational records (e.g. of membership) and social surveys. These multiple sources are analysed using multivariate statistics in an approach that might be described as sociological epidemiology. The available data are not bespoke. Devised for other purposes, the indicators are often less than precise, but Putnam tries to make up for this by using as many different measures as possible.

In Putnam's hands the membership records and surveys do seem to indicate a very marked decline in social connectedness in the US (if that is what they measure) since the 1950s and 1960s. This is evidenced in the spheres of political participation, civic involvement, religious practice, the workplace, volunteering and trust, as well as the starting point of informal social activity. Attention is drawn to the well known fall in cultural participation and rise in consumption (and it is suggested that where there are rises in sports participation it tends to be in sports that are less sociable). Putnam insists that 'in football as in politics, watching a team play is not the same thing as playing on a team' (p114).

...the last several decades have witnessed a striking diminution of regular contacts with friends and neighbours. We spend less time in conversation over meals, we exchange visits less often, we engage less often in leisure activities that encourage casual social interaction, we spend more time watching (admittedly some of it in the presence of others) and less time doing. We know our neighbours less well, and we see old friends less often. In short it is not merely "do good" civic activities that engage us less, but also informal connecting. (Putnam, 2000: 115)

Nor is he persuaded that increases in 'cheque book membership' ${ }^{3}$ and internet contacts effectively counter these other decreases because of the limited interaction involved and avers that 'we are withdrawing from those networks of reciprocity that once constituted our 
communities’ (p184), preferring instead 'communities of limited liability’ (Janowitz, 1967: xvii).

Putnam seeks to assess the relative contribution that different factors have made to this much heralded decline in social capital. His best estimate is that

a) Pressures of time and money account for 10 percent of the decline - these are evidenced through changing work practices, particularly the greater involvement of women in the labour market, which leaves less time for organising and socialising.

b) Suburbanisation, urban sprawl and the associated commuting contribute a further 10 percent through the drain on disposable time.

c) Electronic entertainment (especially television) accounts for 25 percent by privatising leisure lifestyles.

d) Generational change, however, is identified as the major factor, accounting for something like half the reduction in social capital. What Putnam labels as the 'long civic generation' is fast disappearing, to be replaced by baby boomers and Generation $\mathrm{X}$.

e) There is an overlap between (c) and (d), representing a TV generation, that leaves about $15 \%$ to be accounted for by other factors.

He finds no evidence to suggest that changing family structures or 'big government', which have also been proposed as culprits, have contributed in any systematic way to the decline in social capital.

Insisting that the concern with social capital is not just a hankering for the nostalgia of community, Putnam presents data contending that there is a positive correlation between social capital and education, children's welfare, community safety, economic prosperity, health and wellbeing, and involvement in democratic processes. Through social capital collective problems are resolved more easily, business and social transactions are less costly, personal coping is facilitated, information flows are better, and increased awareness promotes tolerance.

If not unambiguously explicating the communitarian roots of his work, Putnam acknowledges that 'social capital is closely related to what some have called 'civic virtue' (Putnam, 2000: 
19). Delanty (2003: 81) takes this observation further when he suggests that there is a 'civic tradition within communitarianism [that] has made social capital and participation in public life central' and he identifies the work of Putnam as central to this strand of political theorising. As Delanty goes on to point out, civic communitarianism is by and large a 'Tocquevillian discourse of the loss of community' and this abiding myth is both nurturing and consuming of those it holds captive. Welch (2001: 238-239) emphasises how '[p]undits, theorists of left and right, and political scientists who stress the importance of social capital...all hark back self-consciously to a few key chapters in Democracy and America'. Indeed, it is Tocqueville's most famous expression 'habits of the heart' that both Bellah et al. (1987) and Putnam (1993) endorse in their discussions of the civic associations necessary for healthy social democracy. Yet, as Welch goes on to point out, it is rarely acknowledged that Tocqueville provided a thoroughgoing critique of the shortcomings of social capital throughout his oeuvre, and particularly in his book The Old Regime, where he depicts the 'dystopia of life gone awry: an intense associational culture within a state infrastructure that both deliberately and inadvertently made cooperation for larger ends impossible’ (ibid).

We would add to this the crucial point that Putnam's version of civic communitarianism is also basically structural functionalist in orientation. Putnam understands social capital as sets of actions, outcomes or social networks allowing people and associations to operate more effectively when they act together. However, as we have already intimated, social capital can have either positive or negative functions for people and/or associations. While he recognises the negative or dysfunctional aspects of social capital, the immense value Putnam puts on social capital comes from its positively functional capacity to transform itself 'from something realized by individuals to something possessed (or not possessed) by either individuals or groups of people' (DeFilippis, 2001: 785). Accordingly there are a number of predictable values that are mobilised by civic communitarians and which are implicit in the idea of social capital. These include a commitment to the 'norm' through the idea of consensus; recognition of obligations, reciprocity and responsibility to others; solidarity; and trust, which is largely drawn through social networks, particularly in the form of voluntary associations, which in Putnam's (1993, 2000) work consist in large part in sport and leisure clubs.

\section{The Appeal of Social Capital}


Some cynics might argue that in winning an audience Putnam is not hampered by his position as a Harvard professor. While this is undoubtedly true there is more to it than that. As already noted, Putnam makes no bones about how the term, social capital, was previously developed by earlier authors. Equally, his observation about the social relations surrounding bowling is a fairly tardy contribution to the discussion within leisure studies, never mind other areas, in the mid to late 1980s about increasingly privatised leisure lifestyles (cocooning). What Putnam did in Bowling Alone was to marry those various debates with a wealth of empirical data.

Possibly it is that weight of data that appealed to senior civil servants, lending the appearance of a more 'scientific' approach to the argument than other writers were providing. We know from long experience in the world of leisure policy the significance of (not) having 'proof' of impacts (PAT 10, 1999; Long et al., 2002). This is particularly significant when dealing with other disciplines / policy areas like medicine and economics. To criticise Putnam because the data that were not collected by him are not perfect is not really fair; he probably has a better appreciation of that than many of his critics. Putnam's position is like that of the epidemiologist - even if individual items are flawed, when you get enough evidence pointing in the same direction it begins to seem compelling. There has been no replication of the exercise in the UK where there is a shortage of comparable, long term data sets, but concerns about similar 'decline' have been reflected in discussions of shortages of volunteers to run sports clubs and youth groups and the continuing move towards privatised lifestyles and social isolation.

The appeal of this thesis to leisure scholars and professionals is that it places an all too often overlooked property of leisure to the fore. Always uneasy about relying on the economic contribution of leisure, here was a means by which it could be seen to contribute to regeneration. Leisure, whether sport, arts or socialising, does not have to be valued only because it can create employment, generate income or improve health, but because it brings different people together.

Social capital and its communitarian underpinnings were ideal for a New Labour project seeking a 'Third Way' between state control and the free market. The thesis propounded in the literature surrounding Bowling Alone purports to speak to many of New Labour's concerns. The key components of the social exclusion agenda are all here: education; 
employment and economic prosperity; community safety; health and wellbeing (PAT 10, 1999), all challenges that sport and the arts are increasingly expected to address. Add to that Putnam's linking of social capital with the support of the democratic process and it can be seen how the arguments might engage a government with growing concerns over the disengagement of the electorate (at least through the ballot box). Part of the appeal of Putnam's contribution lies in his efforts to identify an agenda for 'social capitalists', but in practice this is little more than a series of challenges to various constituencies (citizens, educators, planners/developers, employers, clergy, artists, politicians, etc.) to work out how they can contribute to the project to increase social capital through their own endeavours.

\section{The Limitations of Putnam's Research}

The intuitive appeal of the distinction between bonding and bridging forms of social capital, however, is not reflected in Putnam's exploration of social data. The data simply are not sufficiently detailed to allow such distinctions to be examined, so social capital collapses onto a single dimension (see Warde and Tampubolon, 2002 for a fuller discussion). But the problem of sustaining that distinction is not just an empirical one; it also implies a somewhat simplistic understanding of individuals. The like us / unlike us presumption that lies at the heart of the distinction between bonding and bridging is hard to appreciate given the multidimensionality of any individual (sex, age, class, occupation, ethnicity, sexual orientation, political belief, abilities, interests...). Within my recreational group there are likely to be others with whom I share some of these characteristics, but not others. It may, for example provide me with bridging capital by offering links to people with different skills that may benefit me, yet be racially exclusive and carry the negative characteristics Putnam recognises can come from bonding. Putnam acknowledges that 'bonding and bridging are not either/or categories into which social networks can be neatly divided' (p23), but, having made the point it is lost in the subsequent analysis.

It seems to us that a rather larger problem lies in what Putnam identifies as the biggest single cause of the decline in social capital - the departure of his long civic generation. This demographic sleight of hand does Putnam's cause a disservice as it masks the social processes which, barring genetic mutation, must underlie this value shift. He does offer the common desperate enterprise of war as an explanation for increased solidarity. However, defining World War II as some kind of watershed does little to help us appreciate the social 
processes involved (and does not offer a helpful recipe for reinvigorating social capital). In starting to probe these processes Putnam makes allusions to things like the more libertarian attitudes of the subsequent baby boomers, but elsewhere he insists that liberty goes hand-inglove with fraternity (social capital). Indeed throughout, the problems of attributing cause and separating cause from effect are troublesome (Putnam is not unaware of this).

A closer examination of parts of Putnam's seductive presentation reveals some other rather suspect leaps. Take, for example, Putnam's assertion that changes in work patterns, principally women's increased involvement in full time employment, have contributed 10 percent to the fall in social capital. This is based on the observation that women are responsible for much social interaction and civic engagement at the community level through entertainment at home, volunteering, or running community groups, and that with less disposable time available these have suffered. However, this overlooks the massive injection of social interaction that is provided to women by involvement in the workplace. It is also worth pointing out that Putnam pays little or no attention to the feminist theoretical critique, which argues that communitarians ignore the fact that 'communities' often make claims on their members which are based on extant and often insidious hierarchies of patriarchal domination and subordination. Second, and related to the first point, the units of social relations invoked by communitarians, such as the family, neighbourhood and nation are themselves often found to be 'troubling paradigms of social relationship and community life' (Friedman, 1989: 279).

Putnam also makes claims about the economic benefits of social capital without providing any hard theoretical and empirical evidence (as leisure advocates many of us probably ought to hold our hands up to making similar claims for the contribution of sport and the arts to regeneration). As DeFilippis (2001: 792) remarks, in the mid-nineties Putnam was eulogising the growing significance of 'network capitalism' for the then burgeoning Asian Tiger economies, only to see them collapse in 1997 as a result of the shortcomings of 'crony capitalism'. The same author goes on to make the case that evidence for Putnam's argument is no more convincing when the economic benefits of social capital for the United States are put under the spotlight. This empirically grounded indictment adds fuel to Bauman's (2004) theoretical critique of network capitalism, which argues that even those networks that do exist in contemporary 'liquid' societies are more often than not empty and ephemeral rather than built on anything 'solid'. 
Putnam's theoretical position is also undermined by his research approach. From our own perspective the theoretical position he develops is extremely limited by its lack of qualitative insights. As telling, however, is the charge of methodological individualism implicit in his theorisation of what are basic quantitative insights (Skocpol, 1996; DeFilippis, 2001), underpinned by a positivistic orientation to research. Essentially, Putnam develops a theory of 'community', which is based on quantitative findings from individuals and their interpretations of their individual circumstances, but which he uses in a cumulative way to theorise social networks at various idealised levels, such as 'network', 'community' and 'association'.

\section{Limitations of the Theoretical Basis of Social Capital}

Having repeatedly attempted to draw attention to the benefits to be derived by individuals from the social interaction and exchange represented by participation in the arts and sport (e.g. Long, 1981; Long et al., 2002 ${ }^{4}$ ) it would be surprising if we did not find much in common with Putnam. However, we need to look beyond the arguments reviewed above to the theoretical underpinnings of Putnam's version of social capital which lie in civic communitarianism and structural functionalism. His work has re-animated the wellrehearsed debate between communitarianism and liberal individualism (Etzioni, 1991; Frazer \& Lacey, 1993), and how these might be mapped out in civil society. We take it as given that human lives are built on social relations, but wish to challenge social capitalist ideals of freedom, its link to civil society and the tenets of functionalism before suggesting that 'respect' is what should underpin the work of cultural intermediaries using leisure as a tool for development.

Communitarians express the republican ideal of the public interest and a commitment to positive freedom - as opposed to liberal individualism's recognition of merely negative freedom. Charles Taylor (1979: 157) argues that the liberal individual self is ultimately empty and reveals the sort of identity that has 'arrived at freedom by setting aside all external obstacles and impingements, is characterless and hence without defined purpose'. Bauman (2001) suggests that in an ever more globalising world it was inevitably the case that identity making would become 'a never-ending, always incomplete, unfinished and open-ended activity' and that in the process consumerism would increasingly come to play a pivotal role. 
While social actors become obsessed with their own identities these 'choices' are more than likely to be hollow and identities become palimpsests.

The communitarian response to this dilemma (freedom at the expense of substance) has been to defend what they see as the teleological conception of human nature because they crave deeper, shared identities. Bauman argues the advice of communitarianism is 'choose but choose wisely' (by implication what others have chosen). In that formulation communitarians do not really believe in freedom, only a circumscribed version of an imaginary community built on an oversimplified consensual truth. Bauman's disdain for communitarianism is because when it comes to freedom it is inevitable that communitarian 'choices' and by implication 'difference' will always stand for the power of the community to limit the freedom of social actors (Bauman, 1997). Communitarianism seems to decide who the 'we' and 'they' are, and in associated policy terms 'we' can decide how 'they' need to be helped. The locality is central for it is within local communities that it is presumed a set of shared interests can be cultivated. What communitarianism does is set itself the task of trying to breathe into localities a set of distinct absences - an imagined, imaginary and unimaginable 'community’ (Bauman, 2001) - in order to regenerate spaces of representation as representations of space (Lefebvre, 1991). Not for the poor, then, the choice of making the distinction between their private and public lives - the decisions are made elsewhere.

This has implications for the contested concept of 'civil society'. In our view, the civic communitarian understanding of civil society can be criticised on two counts. As we argued above, one of the problems with civic communitarianism is that there is a slippage in understanding what civil society actually is and what civic communitarians think it should look like, which is invariably located in nostalgia for a mythical past (when people did not bowl alone). Second, civic communitarianism reads civil society in undialectical terms. If liberal individualists can be taken to task for their neglect of the iniquitous role capitalism plays in civil society, communitarians can be criticised for presenting the view that we can talk about civil society in a way that underestimates the pervasive ubiquity of the market and its institutions.

Civic communitarians have also embraced Durkheim's emphasis on social solidarity as a way of realising social cohesion. This allows the integrated realization by community members that 'their distinctive potential lies with the development of co-operative intelligence' (Tam, 
1998: 221), or what others would describe as social capital. The romance of this collective solidarity has been reflected in much leisure studies literature, so it is hardly surprising that the functionalist link between leisure and social capital has been established. Indeed, some like Siisiäinen (2000) have argued that it is only really in relation to sport and leisure associations that Putnam's idea of social capital has any purchase. It may well be that it is in this arena that it has most to offer, but the argument has invariably been dependent on reiterating functionalist conceptions of sport and leisure. There are specific examples of this in the recent leisure studies literature.

In terms of sport, Jarvie's (2003) invocation of social capital and a communitarian philosophy for Scottish sport draws on explicitly functionalist notions of the 'benefits' of sport in its discussion of why sport has contributed to debates about the efficacy of social capital. In his discussion of sport's contribution to civil society, Jarvie outlines some of the ways in which sport has been utilised in both civic engagement and social protest, but in the final part of his discussion he returns to the functionalist singularity that through sport 'people learn to take responsibility, to follow rules, to accept one another, to look for consensus and take on democracy: 'seen in this light sport, is par excellence, the ideal school of democracy (Sport England, 1998: 12)' (Jarvie, 2003: 142). Hemingway (1999) too has been keen to promote the idea that leisure forms can contribute to democracy by building social capital. However, he is also alert to the undemocratic potential of participation that needs to combine money with time to increase utility, and he questions which forms of leisure might stimulate trust, co-operation and connectedness.

Stebbins' (1997; 1999) functionalist orientation is scornful of the perceived atomistic consumerism that pervades many leisure activities - or what Stebbins calls 'casual leisure'. In response, he offers the counterpoint of 'serious leisure' as a kind of leisure activity that is more 'important to the wellbeing of the individual and society' (Rojek, 2000: 18), which he suggests is enjoyed by many self-reliant individuals who practice it as a kind of voluntary association for both private and public ends. For Stebbins (1997) casual leisure is problematic because in the main it is consumptive and involves largely non-productive leisure activities, such as 'hanging around', drinking and smoking. Serious leisure, on the other hand, is essentially a form of leisure participation which is productive and allows the individual to develop a sense of career from their free time activities. 
Stebbins discusses three types of serious leisure: amateurism, hobbyist pursuits and volunteerism. Each of these types of serious leisure has a special capacity to support enduring careers of leisure which are marked by historical turning points and stages of achievement. Serious leisure also tends to be built on the kind of perseverance which enables its participants to build special skills and knowledge and this in turn tends to engender selfconfidence through achievement. There are also some other long-lasting benefits to be had through engaging with serious leisure, which go beyond individual personal selfenhancement, such as material products and long-lasting personal relationships. As Rojek observes, serious leisure is built on a strong sense of moral foundations of social behaviour and tends to give primacy to strongly integrative dimensions of association, companionship and community: in a nutshell, social capital. As such, for Stebbins, serious leisure plays a positive integrative function, and should be understood as 'a vehicle for the cultural and moral reaffirmation of communities as places in which the individual recognises relations of belonging’ (Rojek, 2000: 18).

As Rojek points out, Stebbins ends up reducing serious leisure to being merely a 'rationalpurposive activity'. Indeed, his use of the concept has a very conservative bias; but we would add that it is also underpinned by the functionalist assumption that its contribution to the larger whole of social life makes serious leisure 'a good thing'. Another problem with Stebbins' work is that he, like Putnam, has little to say about the different ways in which voluntary associations, such as sport and leisure clubs, operate in terms of power relations. Drawing on the work of Weber, Siisiäinen (2000) suggests that as well as being oligarchic and bureaucratic, many voluntary organisations are framed by internal conflicts as well as external conflicts with outsiders. In terms of the former he identifies the particular problem with top-down domination from the leadership to rank-and-file members. In relation to both internal and external power relations, we would add to this argument the point that sport and leisure associations, and long established ones in particular, are often inward looking, conservative and over-concerned with themselves; and that getting them to combine with other voluntary associations is very difficult. If that is so, their ability to contribute to social capital is clearly compromised. From these observations what needs to be developed are not so much greater levels of connectedness, but more explicit challenges to extant power relations, including those within leisure associations. 
This functionalist orientation in leisure studies not only neglects the role of power in social networks and voluntary associations, but it also ignores the way social capital in this thesis is divorced from economic capital. For Bourdieu, symbolic and 'real' capitals are always combined to constitute the categories of distinction which both produce and reproduce social class divisions. And it is to Bourdieu's understanding of social capital that we now turn.

\section{A Sociological Understanding of Social Capital}

There are principally two ways of understanding social capital in sociology, which are reflected in the respective works of Bourdieu and Coleman (with Putnam essentially aligned with the latter). Coleman's work is largely concerned with the relationship between education attainment, family and local community life (Coleman, 1961; 1990; 1994; Coleman et al., 1982; and Coleman \& Hoffer, 1987). Although he shares with Bourdieu an interest in rational choice theory, the major difference between his understanding of social capital and Bourdieu's is that like liberal individualism it is distinguished by its emphasis on rational individual action. This focus on unconstrained individualism has been influential on other North American sociological accounts and it represents a major problem in Coleman's work, not least because he assumes that social capital is created by the free will of atomistic individuals. This limitation also suggests some more general issues which Coleman shares with Putnam, most particularly with regard to his understanding of the relationship between individual and collective behaviour and the methodological individualism implicit in his research findings. There is considerable confusion about where social capital resides - at the level of the individual or the community (Uphoff, 2000). We want to argue that Bourdieu offers a more convincing approach because it is located in a sociological framework proper. It not only takes into account individual agency and structural determinants but also in the process dissolves the opposition between the two, as well as dealing with the implications of the material and the symbolic realms of capital (social, cultural and economic) in the process.

If the impact of Putnam's notion of social capital on the Anglo-Saxon world seems pervasive, in France it has been a different story. There, Bourdieu's sociology has long been understood as an enduring gift to those concerned with public policy, sparking a major public debate on inequality, urban decline, unemployment, racism and other related civic issues, including cultural policy. In marked contrast to Putnam, Bourdieu (1993/9) not only offers a more complex understanding of social capital but his research is underpinned by a commitment to 
methodological polytheism (Wacquant, 1998). Although both Putnam and Bourdieu recognise that the social world in all its complexity cannot be reduced to individual indicators, their ways of dealing with this are very different. Putnam opts for multiple statistical indicators to command the attention of policymakers (a route followed by others like Warde and Tampubolon, 2002). Bourdieu on the other hand, recognising that social exclusion and poverty are multifaceted, incorporates qualitative approaches as well to allow the voices of the oppressed to be heard.

Bourdieu's social theory of distinction is an explicit attempt to understand the nature of social class and social class divisions in a complex world in which production has largely given way to consumption. Accordingly, he offers essentially a treatise on taste. For Bourdieu (1984) social class, like 'race', ethnicity and gender, needs to be understood as much by its perceived existence as through its material existence in the classical Marxist sense. To make this synthesis he draws on a theoretical toolkit featuring the concepts of field, habitus and capital. Fields reflect the various social, cultural, economic and political arenas of life, which form their own microcosms of power endowed with their own rules. Power struggles emerge in fields as a result of the belief of social actors that the capital(s) of the field are worth fighting for. Analogous to fluctuations in the stock market, the 'currency' or rate of exchange attached to particular capitals is vulnerable to change as these are continually contested.

In order to synthesise the relationship between the individual and society, or more precisely, his or her relationship with a highly differentiated consumer world constituted by these fields of power, Bourdieu draws on Marcel Mauss's use of the concept of habitus. Bourdieu (2000) suggests that the habitus is an embodied, internalised schema which is both structured by and structuring of social actors' practices, attitudes, and dispositions. The habitus also constitutes and is constituted by social actors' practical sense of knowing the world and it is through their 'feel for the game' of the field that they come to see the social world and the position of themselves and others in that world as unexceptional. Vital to understanding this 'perfect coincidence' is the idea of the social actor's doxa values or 'doxic relation' to the world, which Bourdieu identifies with that tacitly cognitive and practical sense of knowing of what can and cannot be reasonably achieved. In this sense, the habitus constitutes only an 'assumed world' captured as it is through the confines of the individual social actor's 'horizon of possibilities' (Lane, 2000: 194), thereby constraining leisure lives, particularly of the poor suffering a poverty of expectation. 
The practices, attitudes, and dispositions which social actors both adopt and embody ultimately depends on the extent to which they can position themselves in any given field and their particular 'endowment of capital'. For Bourdieu, a capital

is any resource effective in a given social arena that enables one to appropriate the specific profits arising out of participation and contest in it. Capital comes in three principal species: economic (material and financial assets), cultural (scarce symbolic goods, skills, and titles), and social (resources accrued by virtue of membership in a group). A fourth species, symbolic capital, designates the effects of any form of capital when people do not perceive them as such... The position of any individual, group, or institution, in social space may thus be charted by two coordinates, the overall volume and the composition of the capital they detain. (Wacquant, 1998: 221)

In terms of capital, what Putnam overlooks is Bourdieu's important point that what he calls 'the profits of membership' of civic associations and social networks are not available to everybody. As Ball (2003:4) concludes, the point of all 'capitals' - not just social capital - is that they are resources to be exploited and it is their exclusivity in the battle for distinction that gives them their value (being a member of an exclusive golf club, being on the 'right' committee, etc.). In a nutshell: 'People who realize capital through their networks of social capital do so precisely because others are excluded' (DeFilippis, 2001: 801). This apparent failing of Putnam is normally presented as a bonus in that some aspects of social capital are seen not as positional goods in a zero sum game; those contributing to trust, support and security might be seen to be strengthened if shared. Moreover, in using it, social capital is seen to grow.

For Bourdieu, then, social capital cannot be understood in isolation and it, along with the other kinds of capital, is indelibly linked with field and habitus. This crucial point notwithstanding, from Wacquant's discussion we can conclude that social capital has two decisive features: on the one hand it is a tangible resource made by advantage of family, friendship or other kinds of social networks, and on the other, like all forms of capital, it has a symbolic dimension, which contrives to hide networks of power woven into the fibres of familiarity. In the event, Bourdieu's understanding of social capital suggests that it is related to the extent, quality and quantity of social actors' networks and their ability to mobilise 
these, which is always governed by the mutual understanding that any given field is an arena of struggle and it is the battle for distinction that gives social capital its qualities. In this it differs fundamentally from Putnam's concept.

Bourdieu (1984) suggests that the extent to which distinction, and the disparities in power relations it expresses, operate in modern societies is a result of the speciously constructed interests of dominant groups - what he calls the 'cultural arbitrary'. That these groups have the power to classify cultural practices under conditions that put their own tastes to the fore and in terms of their own distaste of the tastes of others, means that they ultimately subject less powerful social actors to a kind of symbolic violence, which not only legitimises the systems of meaning constructed in their own interests, but also maintains extant structures of social inequality. Understood in this light the civic communitarian value of trust as a form of social capital becomes problematic, because as Bourdieu shows us it will inevitably be exploited for gain, in the practice of symbolic power (including symbolic violence) and symbolic exchange (Siisiäinen, 2000).

Put directly in terms of sport and leisure policy, symbolic violence has the effect of normalising the marginality of the poor who are treated as inferior and denied the kind of trust that they could manage public resources for themselves. This in turn not only limits their opportunities for social mobility, but also naturalises their feelings of inadequacy, because their own kind of truth about 'how to go on' does not fit into the existing order. Drawing on his own extensive empirical research with France's urban poor, Bourdieu (1999: 129) elucidates the implications of this state of affairs for understanding the limitations of social capital in localities (socio-cultural fields) experiencing the worst excesses of poverty and social exclusion:

Like a club founded on the active exclusion of undesirable people, the fashionable neighbourhood symbolically consecrates its inhabitants by allowing each one to partake of the capital accumulated by the inhabitants as a whole. Likewise, the stigmatised area symbolically degrades its inhabitants, who, in return, symbolically degrade it. Since they don't have all the cards necessary to participate in the various social games, the only thing they share is their common excommunication. Bringing together on a single site a population homogeneous in its dispossession strengthens that dispossession, notably with respect to culture and cultural practices: the pressures exerted at the level 
of class or school or in public life by the most disadvantaged or those furthest from a “normal” existence pull everything down in a general levelling. They leave no escape other than flight toward other sites (which lack of resources usually renders impossible).

Thus the poor are geographically constrained and may find it difficult to establish bridging capital through normal day to day contact, or indeed their leisure pursuits. Moreover, many in the communities Bourdieu describes simply do not want to know each other.

\section{From the Frozen Communitarian 'Norm' to Respect at a 'Cool Distance’}

Bourdieu's enduring legacy is not merely to leave us with a sociology for understanding that the nature of our modern existence necessitates us living with contingency and difference but is also suggestive of a politics which points to ways in which the more enduring conditions of poverty can be challenged. We want to suggest that there is a pivotal role for Bourdieu's sociology in the process of engaging with poor social groups through leisure, particularly through the role of what Bourdieu (1984) identifies as the 'new cultural intermediaries'. These are members of the new middle classes who engage in the promotion and transmission of a 'happening' world to 'a larger audience and collude with the intellectuals to legitimate new fields such as sport, fashion, popular music, and popular culture as valid fields of intellectual analysis' (Featherstone, 1991: 44). But our view is that their role must go beyond their narcissistic fascination with lifestyle and identity. As Featherstone has argued, these cultural intermediaries have to some extent been effective in collapsing some of the most enduring distinctions and symbolic hierarchies between 'high' and 'low' cultures of taste and in opening 'information channels between formerly sealed off areas of culture' (ibid: 10). It is very clearly the case that there could be a key role for cultural intermediaries in the arena of social exclusion if they go beyond the largely self-absorbed communicative role identified by Bourdieu.

We want to suggest that communication has become much more important in engaging with issues of social exclusion in a world where respect is arguably the pivotal value (Sennett, 2003). The dignity of self-respect has always been important to individuals, but today respect is much more to do with how we imagine others see us. With this the whole process of equality is transformed. If social capitalists have been slow in recognising the value of 
respect for community work, those living in the poorest localities have not. A key study by Bourgois (1995) has shown that for young men living in such areas, losing what were once the formative structures for gaining respect in the community, such as the work role and the ability to provide for the family, coupled with the concomitant growing importance of consumption in their lives (Collison, 1996), has thrown up lifestyles involving substitutes where they can search for 'cool respect' through spectacular consumption in the form of drug taking and drug dealing, sexual promiscuity and violence.

If, as Bauman (2001) suggests, 'cool' can on the one hand imply a 'flight from feeling' (he sees it as ignoring responsibility for others), it can also be understood as a form of respect for the values of the other, for the values of difference. In this second meaning 'cool' does not merely imply secession for the sake of 'needing more space for myself' or the flight from 'the real messiness of intimacy', it also assumes a sense of propriety, which involves knowing just how close one needs to get in order to both respect and gain the respect of the other. The ideal 'cool distance' cannot be guaranteed in advance, but it needs to be neither too far, nor too close, so as not to worry the other and also not to lose the potential benefits of what a good relationship with that other can offer.

Sennett (2003) highlights the lack of mutual respect which tends to pervade the provision of services to those who are forced to abide by or are dependent upon bureaucratic welfare organisations and their representatives. In a world that is not only saturated with difference and contingent social relationships, pervaded by inequality, gaining respect becomes a matter of 'performativity', of composing the appropriate kind of performance (Lyotard, 1984). But for both Lyotard and Bauman (1997) respect takes a liquid form, confirmed via the market through consumption and the major problem is that 'cool' is always governed by an ephemeral currency. Yet what we want to suggest is that cultural intermediaries recast as community development workers can play a pivotal role in generating communication between different individuals and 'communities' at the same time as being respectful of their need to keep a 'cool distance'. Our arguments come back together again in asserting the futility of any efforts to impose authority in a top down way. The various forms of social capital may be necessary to deliver social benefits/change, but these will not be sufficient without people feeling they share 'the project' and having access to the other forms of capital.

\section{Conclusions}


The association with social capital has been useful to Sport England in rationalising its Active England programme, and has rejuvenated the interest of the Central Council for Physical Recreation in volunteering. Such evidence confirms that it is difficult to gainsay the argument of the social capital thesis that in general we are better off if we have contact with those around us, thereby promoting social support and mutual trust, and with other groups to promote understanding and access to skills and avenues of power. It has an allure for all political positions, and when it is good it can be very, very good, but when it is bad it can be horrid.

In this paper we have tried to tease out some of the issues of the social capital thesis of Putnam, its often unarticulated link with communitarianism (the word does not even appear in the index of Bowling Alone), and Putnam as made into policy. Social capital should presumably reflect the ability to act (co-operatively) to achieve desired social goals. The presumption that this resides in social networks is a dangerous one. Social connectedness is undoubtedly important, but not sufficient. Even the addition of 'hierarchical' (World Bank, 2003) or 'linking' (Office for National Statistics, 2001; Woolcock, 2001) elements that represent connections with people in power may not allow people to have a say in shaping the society into which they are to be 'included' (Long et al., 2002).

There is an inconsistency in the protestations of promoting trust at local level while successive governments have centralised powers. The everyday expression of the anticommunitarian position would take the form of community-building (sic) without the sameness of prescriptive top-down politics or the rhetoric of 'community' appropriated for political ends. Rather than the internalised duty-bound form of difference communitarians are concerned with, it might be more appropriate to address what is external to the poorest groups, how awful life is on the outside of them - living in the social, cultural, political and economic deprivation of urban spaces with their very life-bloods sucked out of them. Community development through leisure initiatives has a responsibility to operate in the worlds in which people actually live, rather than trying to transplant them to a mythical world that only exists in the minds eye of civic communitarians.

Indeed it can be argued that the once emancipatory welfare services can too easily become a second-rate and repressive regime, subject to the 'gaze' of those employed by the state: the 
DSS officer, the community sports development worker, the GP, the social worker, the probation officer, and so forth that collectively 'police' the 'flawed consumers' (Bauman, 1995). This approach is 'concerned with techniques to identify, classify, and manage groupings sorted by dangerousness' (Feeley \& Simon, 1992: 452). As Foucault (1977) points out, this modern form of repressive social control which always operates at a distance has been made possible through the construction of what Giddens (1991) has identified as 'experts' and 'expert systems' which claim the necessary authority to command the power/knowledge of governmentality. For Bauman (1995: 100), 'distance' is of the utmost importance here since it is not merely used to differentiate 'us' from 'them', it also allows 'us' to construct 'them' as 'the objective of aesthetic, not moral evaluation; as a matter of taste, not responsibility'. This process marks the comfortable but anxious majority's disengagement from a commitment and responsibility for the poor, and certainly not the sharing of bridging capital.

Sennett (2003) points out that 'being somebody' today is about finding one's value in the eyes of other people; he has also found the ideal metaphor that should be the watchword of all community initiatives - respect. This alternative politics of difference would centre mutual respect as a value worth fighting for and it would open up new possibilities for developing alliances better able to tackle the material and symbolic struggles identified in the work of Bourdieu. The cultural intermediaries have a crucial role to play in this interpretive process. To draw effectively on their skills, however, would require much more than merely parachuting community workers into localities, as is the case at the moment - following Putnam's model community sport/arts/leisure development workers are dropped into a locality, carry out a 'community audit' to gather a range of quotidian detail, get individuals and agencies networking, then get out before their curiosity is exhausted. Such a method is limited because it cannot hope to build the kind of trust and respect through social networks that is needed in localities where most people do not know each other and do not care to share the full extent of each other's lives.

The main thing that most people who live in localities suffering the worst excesses of deprivation have in common is their poverty. In these localities there is often little in the way of the 'norm', solidarity or trust, and it may be eminently sensible to keep yourself to yourself. Bauman (2004) argues that it is often the case that trust is recast as naivety and is replaced by suspicion and 'let's wait and see how they work' joint alliances, which tend to be 
entered into with a 'cancellation option' in mind. Not for anybody the embarrassment of being made to look stupid after having been taken for a fool. In order to bring about some semblance of egalitarianism in a world that seems at the present moment irrevocably unjust the only logical way forward is to create the kinds of social, cultural and political spaces that speak to that shared fate.

The rudiments of what this process should entail in practice is explored in more depth by Blackshaw and Crabbe (2004), but the point we want to make here is that it is vital to recognise that community leisure initiatives of the kind we are suggesting must be underpinned by a combination of effective communication and compassionate understanding that is able to cross cultural divides, and in a way that can generate mutual respect. An approach that is able to ask seriously empathetic 'what would they think about this issue from the outlook of their lives?' questions while never losing sight of the quotidian details of lives on the margins, would give the development work of community leisure practitioners a new credibility as well as respect. And in our view leisure has a key role to play in this process, because it does have the potential to communicate across those cultural boundaries that divide communities in a way that is at the same time respectful of the differences that separate them.

\section{References}

Arai, S. \& Pedlar, A. (2003) Moving beyond individualism in leisure theory: a critical analysis of concepts of community and social engagement. Leisure Studies, 22 (3) 185-202.

Ball, S. J. (2003) 'It's Not What You Know: Education and Social Capital' in Sociology Review, November.

Bauman, Z. (1995) Life in Fragments: Essays in Postmodern Morality. Oxford, Blackwell.

Bauman, Z. (1997) Postmodernity and its Discontents, Cambridge: Polity Press in association with Blackwell.

Bauman, Z. (2001) Community: Seeking Safety in an Insecure World. Cambridge, Polity 
Press.

Bauman, Z. (2004) Wasted Lives: Modernity and its Outcasts. Cambridge: Polity Press.

Bellah, R. Madsen, R., Sullivan, W., Swidler, A. and Tipton, S. (1987) Habits of the Heart. Berkeley: University of California Press.

Blackshaw, T. and Crabbe, T. (2004) New Perspectives on Sport and 'Deviance': consumption, performativity and social control. London: Routledge.

Bourdieu, P. (1984) Distinction: A social critique of the judgement of taste. London: RKP.

Bourdieu, P. (1993, trans. 1999) The Weight of the World: social suffering in contemporary society. Cambridge: Polity Press.

Bourdieu, P. (2000) Pascalian Meditations. Cambridge: Polity Press.

Bourgois, P. (1995) 'In Search of Masculinity: Violence, Respect and Sexuality among Puerto Rican Crack dealers in East Harlem', in T. Jefferson and P, Carlen (Eds) Masculinities, Social Relations and Crime, Special Issue of the British Journal of Criminology 36 (3) 412-27.

Cantle, T. (2001) Community cohesion: A report of the independent review team. London: Home Office.

Clarke, J. and Critcher, C. (1985) The Devil Makes Work: leisure in capitalist Britain. London: Macmillan.

Coleman, J. S. (1961) Adolescent Society: the social life of a teenager and its impact on education. New York, Free Press.

Coleman, J. S. (1990) Equality and Achievement in Education. Boulder, Westview Press. 
Coleman, J. S. (1994) Foundations of Social Theory. Cambridge (MA), Belknap Press (Harvard University Press).

Coleman, J. S., Hoffer, T. and Kilgore, S. (1982) High School Achievement: Public, Catholic and Private Schools Compared. New York, Basic Books.

Coleman, J. S. and Hoffer, T. (1987) Public and Private Schools: the Impact of Communities. New York, Basic Books.

Collison, M. 'In the Search for High Life: Drugs, Crime, Masculinity and Consumption’ in T. Jefferson and P, Carlen (Eds) Masculinities, Social Relations and Crime, Special Issue of the British Journal of Criminology 36 (3) 428-44.

DeFilippis, J. (2001) 'The Myth of Social Capital in Community Development' in Housing Policy Debate 12 (4) 781-806.

Delanty, G. (2003) Community. London: Routledge.

Denham, J. (2001) Building cohesive communities: a report of the ministerial group on public order and community cohesion. London: Home Office.

Durkheim (1902) The Division of Labour in Society. New York, Free Press.

Etzioni, A. (1993) The Spirit of Community. London, Fontana.

Featherstone, M. (1991) Consumer Culture and Postmodernism. London: Sage.

Feeley, M. \& Simon, J. (1992) 'The new penology: Notes on the emerging strategy of corrections and its implications', Criminology 30 (4) 449-474

Foucault, M. (1977) Discipline and Punish: the Birth of the Prison, Harmondsworth: Penguin. 
Frazer, E. \& Lacey, N. (1993) The Politics of Community: a feminist critique of the liberalcommunitarian debate. Toronto: University of Toronto Press.

Giddens, A. (1991) Modernity and Self-Identity: Self and Society in the Late Modern Age, Cambridge: Polity Press.

Hall, J. (2003) ‘A Very Civic Servant’, Society Guardian 1/10/03, p6-7.

Hemingway, J. (1999) Leisure, social capital and democratic citizenship, Journal of Leisure Research, 31 (2) 150-165.

Janowitz, M. (1967) The Community Press in an Urban Setting: the social elements of urbanism $\left(2^{\text {nd }}\right.$ Ed.). Chicago, University of Chicago Press.

Jarvie, G. (2003) Communitarianism, sport and social capital: neighbourly insights into Scottish sport, International Review for the Sociology of Sport 38 (2) 139-153.

Lane, J. F. (2000) Pierre Bourdieu: A Critical Introduction. London, Pluto Press.

Lefebvre, H. (1991) The Production of Space. Oxford, Blackwell.

Long, J. (1981) Leisure as a tool for community development and the opiate of the masses, in A. Tomlinson (ed) Leisure and Social Control. Eastbourne, Brighton Polytechnic, pp161165.

Long, J., Welch, M., Bramham, P., Hylton, K., Butterfield, J. \& Lloyd, E. (2002) Count Me In: the dimensions of social inclusion through culture and sport. Report to the Department for Culture Media and Sport. http://www.lmu.ac.uk/ces/lss/research/countmein.pdf

Lyotard, J-F. (1984) The Postmodern Condition: A Report on Knowledge, Minneapolis: University of Minnesota Press.

Office for National Statistics (Harper, R) (2001) Social Capital: a review of the literature. London, ONS. 
http://www.statistics.gov.uk/socialcapital/downloads/soccaplitreview.pdf

Policy Action Team 10 (1999) Arts \& Sport: a report to the Social Exclusion Unit. London, DCMS.

Putnam, R. D. (1993) 'The Prosperous Community: Social Capital and Public Life' in The American Prospect 4 (13) 11-18.

Putnam, R. D. (1995) 'Bowling Alone: America’s Declining Social Capital’ in Journal of Democracy 6 (1) 65-78.

Putnam, R.D. (2000) Bowling Alone: the collapse and revival of American community. New York: Simon \& Schuster (Touchstone).

Rojek, C. (1985) Capitalism and Leisure Theory. London, Tavistock.

Rojek, C. (2000) Leisure and Culture. Basingstoke, Macmillan.

Seliger, M. (1976) Ideology and Politics. London: Allen and Unwyn.

Selznick, P. (1998) Social justice: a communitarian perspective, in A. Etzioni (ed) The Essential Communitarian Reader. New York, Rowman \& Littlefield, pp. 61-72.

Sennett, R. (2003) Respect: the formation of character in an age of inequality, London: Allen Lane.

Siisiäinen, M. (2000) ‘Two Concepts of Social Capital: Bourdieu versus Putnam’. Paper presented a the ISTR Fourth International Conference 'The Third Sector: For What and For Whom?’ Trinity College Dublin July 5-8.

Skocpol, T. (1996) ‘Unravelling From Above’ in American Prospect 20-25 March-April.

Sport England (1998) The Value of Sport. London, Sport England. 
Stebbins, R. (1997) Casual Leisure: A Conceptual Statement, Leisure Studies, 16 (1) 17-26.

Stebbins, R. (1999) Serious leisure. In T.L. Burton \& E.L. Jackson (eds) Leisure Studies: Prospects for the Twenty-First Century, State College,(Pen): Venture Publishing.

Tam, H. B. (1998) Communitarianism: a new agenda for politics and citizenship. Basingstoke: Macmillan.

Taylor, C. (1979) Hegel and Modern Society Cambridge: Cambridge University Press.

Thompson, J. B. (1984) Studies in the Theory of Ideology. Cambridge: Polity Press.

Uphoff, N. (2000) Understanding social capital: learning from the analysis and experience of participation, in P Dasgupta \& I Serageldin (eds) Social Capital: a multifaceted perspective. Washington DC, The World Bank.

Wacquant. L. J. D. (1998) 'Pierre Bourdieu’ in Stones, R. (ed) Key Sociological Thinkers. Basingstoke: MacMillan.

Warde. A. and Tampubolon , G. (2002) 'Social Capital, Networks and Leisure Consumption', in The Sociological Review 155-180

Welch, C. (2001) De Tocqueville. Oxford: Oxford University Press.

Woolcock, M. (2001) The place of social capital in understanding social and economic outcomes, Canadian Journal of Policy Research, 2 (1) 11-17.

World Bank (2003) Social Capital and Development.

www.iris.umd.edu/socat/concept/concept.htm accessed 01/08/03.

\footnotetext{
${ }^{1}$ Thus, for example, the Cantle review team was charged to address how to develop: social capital; community networks and capacity; and individual skills, confidence and self esteem. The parallel Denham Report (2001: 28) on community cohesion and building shared social capital, concluded that:
} 
Sporting and cultural opportunities can play an important part in re-engaging disaffected sections of the community, building shared social capital and grass roots leadership through improved cross-cultural interaction.

\footnotetext{
${ }^{2}$ We recognise that there are many variants of communitarianism that are adopted by both those of the 'left' and the 'right'. However, Selznick (1998) identifies some of the common characteristics as being equality, mutuality, stewardship, inclusion and social justice as being the foundations of community. Hence the broad appeal; these are hard to object to. Etzioni's (1993) communitarian manifesto could be sub-titled 'in search of a moral revival'. He wants to 'shore up our values, responsibilities, institutions and communities' (p2) and ensure that individuals discharge their duties to the polity and responsibilities to the community.
}

One of the Communitarian goals is to create a more inclusive society where despite the high concentrations of labour and much geographical mobility there are 'new communities' that 'sustain a web of social bonds, a Communitarian nexus' (Etzioni, 1993: 119). However, Etzioni does not advocate a return to the gemeinschaft of the traditional community, enthusing instead about a 'new gemeinschaft' without the earlier repression (p122). He notes that environments can be made more 'community friendly by the provision of sport and leisure facilities to satisfy the 'need for social connectedness' (p128), and also draws attention to the need for associated voluntary contributions to the community. Elsewhere, a favourable discussion of the relationships between leisure and communitarianism is offered by Arai and Pedlar (2003), who, like Putnam, elevate the active (singing in the choir) over passive consumption (listening to a recording) on the basis that in the latter the individual is separated from the community.

${ }^{3}$ Many of those organisations that have bucked the trend of declining membership are identified as requiring only a regular cheque from their members.

${ }^{4}$ The functionalist position has long been the subject of extended critique in Leisure Studies (e.g. Clarke and Critcher, 1985; Rojek, 1985). Its key characteristics are - as far as the current paper is concerned - associated with the way in which social activities are understood as contributing to satisfying basic social needs and to maintaining the stability of a social system. 